\title{
EXPERIENCE OF MANAGEMENT OF LIVER HYDATID DISEASE IN A TERTIARY CARE HOSPITAL- COMPARISON OF SURGICAL TECHNIQUES
}

\author{
Aparajita Mookherjee ${ }^{1}$, Bharathi Kantamani2, Moonish V. S3, Preethi Chandran ${ }^{4}$ \\ 1 Professor, Department of General Surgery, Vydehi Institute of Medical Sciences \& RC. \\ ${ }_{2}^{2}$ Post Graduate, Department of General Surgery, Vydehi Institute of Medical Sciences \& RC. \\ 3 Post Graduate, Department of General Surgery, Vydehi Institute of Medical Sciences \& RC. \\ ${ }^{4}$ Post Graduate, Department of General Surgery, Vydehi Institute of Medical Sciences \& RC.
}

ABSTRACT

\section{BACKGROUND}

Hydatid disease is an endemic condition in several parts of the world. Owing to ease of travel, surgeons in non-endemic areas are also encountering the disease. Hence, should be aware of the optimum treatment protocols. Surgery is the gold standard of management. In recent years laparoscopic surgery has become the preferred mode of surgery with much less complications and the additional advantage of early recovery. This study evaluates the efficacy and outcomes of minimally invasive laparoscopic surgery over open method in a tertiary care hospital.

\section{METHODS}

Between January 2014 and June 2015, total of 60 patients of liver hydatid disease were selected for surgery in this tertiary care hospital, 30 patients each underwent open and laparoscopic surgery, with the exclusion criteria being up to less than $3 \mathrm{cms}$ in size, extra hepatic hydatid cysts and patients unfit for general anaesthesia. The clinical presentations, laboratory findings, Operative findings and post-operative complications were compared.

\section{RESULTS}

A female preponderance was noted (56.66\%) with maximum number of patients in the $4^{\text {th }}$ decade (40\%), common presenting symptoms were pain and mass per abdomen. Majority of patients presented with single hydatid cyst (70\%) with involvement of right lobe in $56.66 \%$. All patients underwent pericystectomy (Open or laparoscopic) with mean duration of 14 days hospital stay following open surgery and 6days following laparoscopic surgery. All patients with preoperative cysto-biliary communication underwent open surgery. Spillage was the common intra operative complication in $13.3 \%$ of laparoscopic patients. Postoperative biliary leak was seen only in the open surgery patients with cystobiliary communication (13.3\%). Followup period ranged from 6 months to 1 year with no recurrence observed during this period in either group.

\section{CONCLUSION}

Early recovery, shorter hospital stay, minimum morbidity and faster return to work are the definite advantages of laparoscopic surgery and hence it should be ideally considered as a safe and efficacious treatment modality in cases of uncomplicated hydatid disease.

\section{KEYWORDS}

Hepatic Hydatidosis, Laparotomy, Laparoscopy.

HOW TO CITE THIS ARTICLE: Mookherjee A, Kantamani B, Moonish VS, et al. Experience of management of liver hydatid disease in a tertiary care hospital: comparison of surgical techniques. J Evolution Med Dent Sci 2016;5(2):148-153,

DOI: $10.14260 /$ jemds/2016/35

\section{INTRODUCTION}

Human Hydatid disease or Cystic Echinococcosis (CE) has been known since the times of Hippocrates.(1) It is a parasitic disease of worldwide distribution and incidence in the sheep rearing areas, including the Indian subcontinent. Physicians and surgeons often encounter this disease because of increased travel and migration.(2) It is carried by the parasite Echinococcosis granulosus, a Cestode that lives in the small intestine of dogs and other canines (Definitive host).

Eggs are eliminated in the faeces and when ingested liberate the larvae in the duodenum of the intermediate hosts.

Financial or Other, Competing Interest: None.

Submission 15-12-2015, Peer Review 16-12-2015,

Acceptance 02-01-2016, Published 07-01-2016.

Corresponding Author:

Dr. Aparajita Mookherjee,

Flat no-B 206,

Definer Serene Drive,

Pettanahalli, Hoskote,

Bangalore-562114.

E-mail: aparajita.mb@gmail.com

DOI:10.14260/jemds/2016/35
Intermediate hosts can be Sheep or Goat (Pastoral hydatidosis) or Rein door/Moose (Sylvan hydatidosis). Humans are accidental intermediate hosts. ${ }^{(3)}$

The most common site of occurrence of hydatid cysts in humans is the liver (50-93\%).(4) Liver hydatid disease is mostly asymptomatic in the early stages. If left untreated, the cysts grow in size and eventually cause complications likecysto biliary fistula or communication, rupture into the peritoneal cavity and seeding of daughter cysts, leading to disability and morbidity. Only in exceptional cases does spontaneous healing occur due to parasitic death and calcification.(5)

Surgery remains the gold standard therapy for Liver Hydatidosis, despite significant advances in medical management and interventional radiology.(6) With time, the treatment of abdominal hydatid disease is undergoing revolutionary changes and the era of open surgery with its associated large incision, post-operative complications and prolonged hospital stay is now being challenged by minimally invasive laparoscopic surgery.(7) 
Many controversies regarding patient selection criteria, surgical technique and follow up protocol, about the role of laparoscopic surgery have not been resolved completely due to scarce worldwide experience. ${ }^{(8)}$

Hence, this study presents a comparison of the outcomes of open versus laparoscopic procedure in the context of a single institutional experience.

\section{MATERIALS AND METHODS}

Between January 2014 and June 2015, 60 patients with liver hydatid disease underwent surgery in the hospital; 30 patients in group I underwent laparoscopic surgery and 30 patients in group II underwent open surgery. All patients with liver hydatid disease were included in the study, only excluding patients less than 18 yrs. age, unfit for general anaesthesia, having cysts less than $3 \mathrm{~cm}$ in size and with associated extra hepatic hydatid disease (Lungs, kidney etc.). Diagnosis of liver hydatidosis was done by USG of abdomen and further confirmed by CECT scan of abdomen for confirmation of exact number, size, depth and complications of cysts. Patients with preoperative evidence of intrabiliary rupture were excluded from the laparoscopic group and included in the open surgery group.

\section{Intrabiliary rupture was suspected preoperatively in the} following cases.

1. Liver hydatid cyst with Gharbi type 2 during USG abdomen associated with hepatic cytolysis and cholestasis changes.

2. Liver hydatid cyst with Gharbi type 2 or type 4 during USG abdomen associated with presence of jaundice during hospital admission or in the medical history.

3. Liver hydatid cysts with Gharbi type 2 or type 4 during USG abdomen associated with CBD dilatation exceeding $10 \mathrm{~mm}$ and elevated cholestatic levels.

4. Liver hydatid cysts with Gharbi type 2 or type 4 during USG abdomen and the presence of echogenic material within the CBD.

All patients received preoperatively medical management with tablet Albendazole ( $400 \mathrm{mg}$ twice a day) for at least 4 weeks. Following surgery postoperative medical management with tablet Albendazole was continued for 4 cycles of 28 days with a gap of 14 days between 2 cycles.

\section{Surgical technique for Group 1}

All patients were opened by Hasson's technique following a transumbilical incision. Three ports - umbilical camera $10 \mathrm{~mm}$ port, epigastric Palanivelu hydatid system $12 \mathrm{~mm}$ port and right midclavicular line $5 \mathrm{~mm}$ working ports were placed for right lobe hydatid disease and 4 ports -supraumbilical $10 \mathrm{~mm}$ port camera port, epigastric Palanivelu hydatid system $12 \mathrm{~mm}$ port, right midclavicular line $5 \mathrm{~mm}$ working port and left midclavicular line $5 \mathrm{~mm}$ working port were placed for left lobe hydatid disease (Fig I and II).

Following $\mathrm{CO}_{2}$ insufflation and creating a pneumoperitoneum (pressure of $12 \mathrm{~mm}$ of $\mathrm{Hg}$ ) position of cysts were confirmed and adhesiolysis done between cyst and surrounding structures. Cyst evacuation was done using Palanivelu hydatid trocar system (Fig III and IV) introduced directly transabdominally over the cyst. Once inside the abdomen the trocar was removed, cannula tip made to touch the cyst surface and maintains tight contact by applying suction through a side channel.
A $5 \mathrm{~mm}$ suction nozzle was introduced into the cannula and fitted to another suction machine. Following puncture of cysts all spillage was sucked through the side cannula. Through the PHS system, the cyst cavity was continuously irrigated with $0.04 \%$ Chlorhexidine scolicidal agent to remove all debris, fragmented laminated membrane and daughter cysts. Telescope was reintroduced through the trocar into the cavity to confirm any remnants of daughter cysts, hydatid sand and to confirm for any cysto-biliary communication. The cavity was re-irrigated with chlorhexidine for a holding time of 10 minutes and reaspirated, procedure repeated for a few times till the returning fluid was free of all debris.

In the absence of any cystobiliary communication $(<5 \mathrm{~mm})$, the cyst wall was deroofed (partial pericystectomy), the cavity was packed and sutured with omentum and an intra-abdominal drain was kept in situ.

None of the patients had any evidence of biliary communication (All patients were included in group II following pre-operative evaluation) and 2 of the patients had to be converted to open surgery (Due to iatrogenic liver injury).

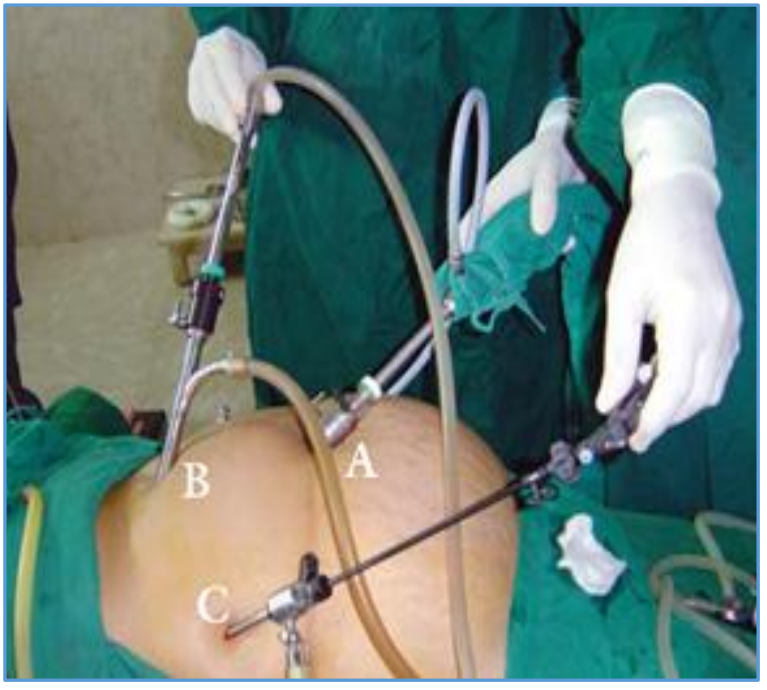

Fig. 1

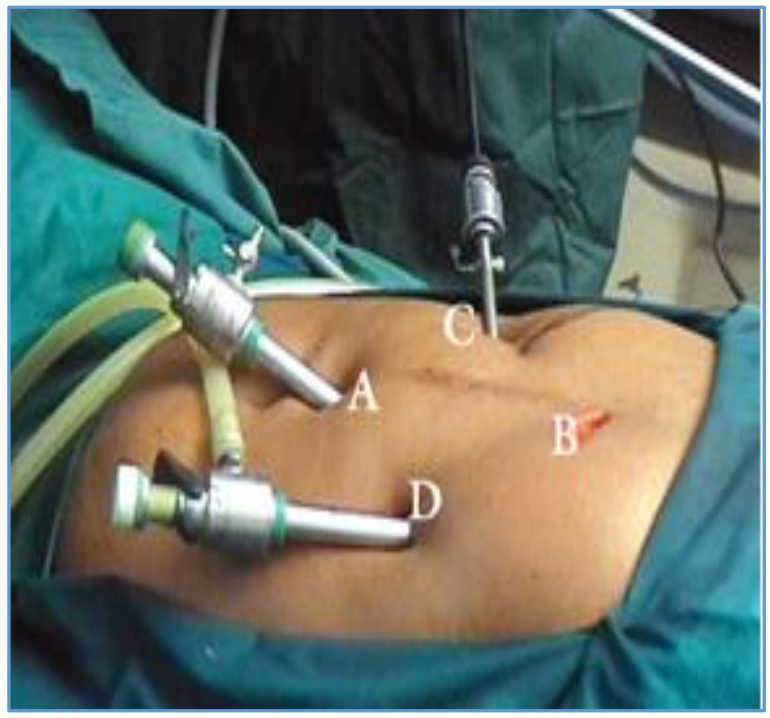

Fig. 2 


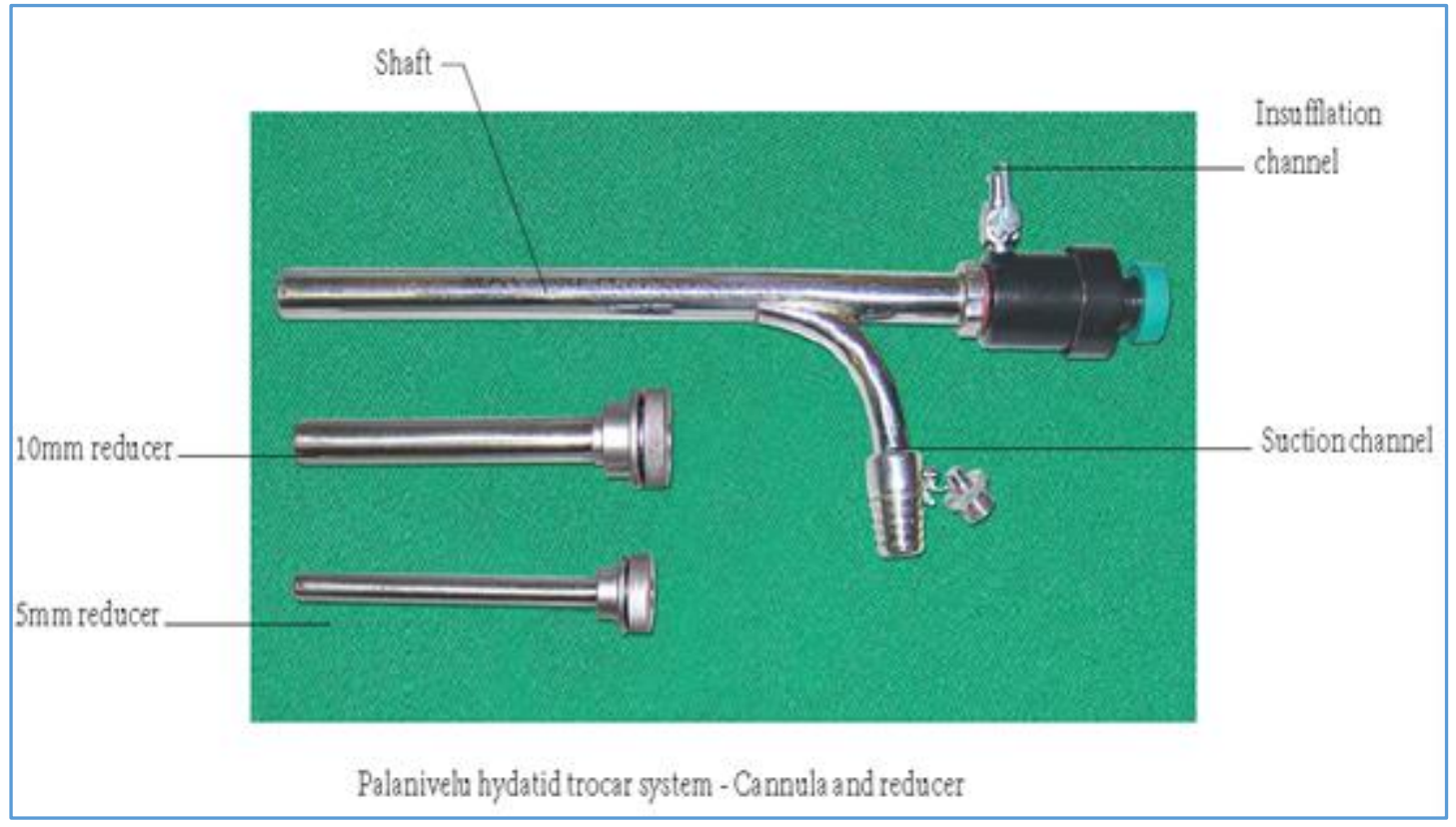

Fig. 3

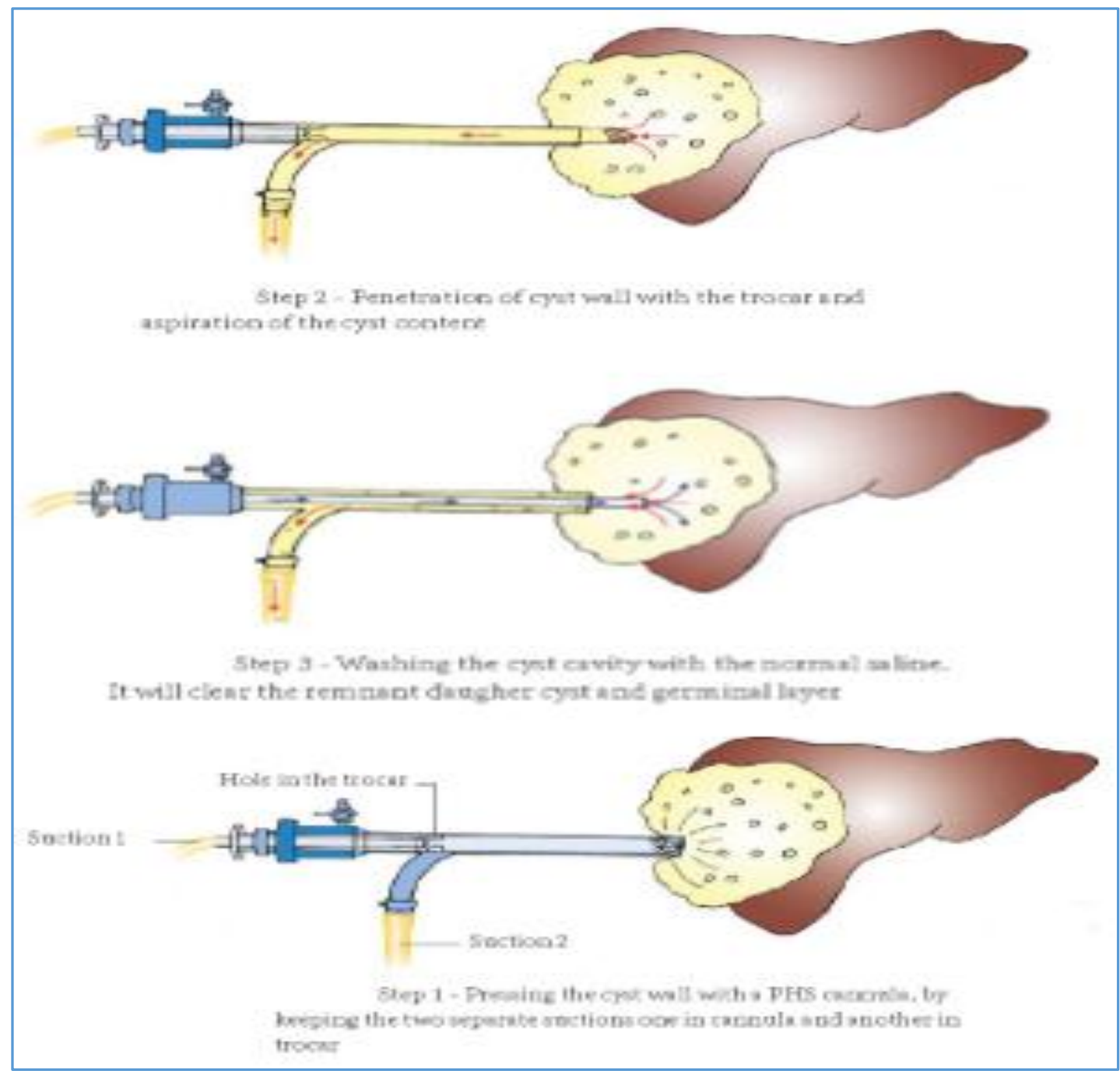

Fig. 4 


\section{Surgical technique for Group II}

Choice of incision was either right subcostal (Kocher's) or midline depending on the cyst location. After isolation of cyst, abdominal cavity was packed with $0.04 \%$ chlorhexidine soaked packs and then the cyst cavity was punctured, all contents aspirated and the same scolicidal agent injected into the cyst for a holding time of 5-10 minutes. These steps were repeated for 2-3 times till returning fluid was clear, followed by pericystectomy (partial/complete). In the 8 patients with overt cysto biliary communication $(>5 \mathrm{~mm})$, the openings were closed with 2-0 Vicryl and then all cavities were packed with omentum and closure was done over a suction drain.

All patients were allowed orally on appearance of bowel sounds and drain removal done after 48-72 hours when the contents were $20-25 \mathrm{ml}$ over $24 \mathrm{hrs}$.

\section{STATISTICAL ANALYSIS RESULTS}

Patients from both the groups were found comparable in terms of age, gender, clinical presentation, number of cysts and size of the cysts. Maximum patients were in the age group of $31-50$ years numbering $36(60 \%)$ in both the groups. Female preponderance was seen in 34 cases $(56.6 \%)$. Pain was the common presenting symptom in $42(70 \%)$ patients followed by mass per abdomen in $6(10 \%)$ of cases; $42(70 \%)$ patients had single cyst, followed by 2 cysts in $14(23.3 \%)$ patients. right lobe was predominantly involved in 34 (56.6\%) patients and the mean cyst diameter was $9 \mathrm{cms}$ in $42(70 \%)$ cases. (Table I).

\section{Comparison of intraoperative complications, post-operative morbidities and complications}

In laparoscopic group (Group I), spillage was seen in 4 patients $(13.3 \%)$ and 2 patients (6.7\%) suffered iatrogenic liver injury. Both these cases had to be converted to open surgery for repair of the liver injury. Spillage could be managed laparoscopically.
In group II patients intraoperative bleeding and spillage was seen in 2 patients $(6.7 \%)$ each. There was no liver injury and 8 patients $(13.3 \%)$ were found to have evident cystobiliary communication ( $>5 \mathrm{~mm}$ in size) as was diagnosed preoperatively and hence patients were included in the open surgery group.

Requirement of postoperative analgesia (Injection or tablet Diclofenac 50mg BD) was for a mean of 2.5 days in group I patients and 6 days in group II patients $\left(\mathrm{P}<0.001^{* *}\right)$. In all group I patients, post-operative drain removal was done after 3-4 days, whereas following open surgery average time for drain removal was 4-6 days, except in 8 patients with cystobiliary communication (9-10 days).

There was a significant difference in the post-operative complications (Mainly biliary leak and surgical site infection) none of the laparoscopic group patients had any complications whereas in group II, 8 patients (13.35) had biliary leak (due to cysto biliary communication) and 10 patients (33.3\%) had surgical site infections (Table II).

\section{Hospital Stay and Recurrence}

Early mobilization ( $1^{\text {st }}$ and $2^{\text {nd }}$ day) was seen in all the laparoscopic group patients, where as in group II most patients were mobilized after $2^{\text {nd }}$ post-operative day. Hence, duration of hospital stay was shorter for group I patients (mean of 4 days) while following open surgery patients had a mean stay of 8 days in the $12(10 \%)$ (Uncomplicated patients) while in the remaining $18(60 \%)$ patients with complications the mean stay was 14 days. The stay was significantly longer for group II $\left(\mathrm{P}<0.001^{* *}\right)$.

All patients were followed up to a duration of 6 months 12 months and no recurrence was observed in either group during this period.

Comparison of study variables in the 2 groups studied is shown in Table III.

\begin{tabular}{|c|c|c|c|c|c|}
\hline \multirow[t]{2}{*}{ Parameters } & \multicolumn{2}{|c|}{ Laparoscopic Group } & \multicolumn{2}{|c|}{ Open Group } & \multirow[b]{2}{*}{ P-value } \\
\hline & $n=30$ & (\%) & $n=30$ & $(\%)$ & \\
\hline 1.Age (years) & & \multicolumn{2}{|c|}{$1<-2$} & \multirow{6}{*}{0.387} \\
\hline$<30$ & 2 & 6.7 & 4 & 13.3 & \\
\hline $31-50$ & 20 & 66.67 & 16 & 53.3 & \\
\hline$>50$ & 8 & 26.67 & 10 & 33.3 & \\
\hline Mean age (yrs.) & & & & & \\
\hline & \multicolumn{2}{|c|}{$46.67+9.76$} & \multicolumn{2}{|c|}{$42.67+14.67$} & \\
\hline 2.Sex & & & & & \\
\hline Male & 12 & 40.0 & 14 & 46.7 & \\
\hline Female & 18 & 60.0 & 16 & 53.3 & 0.713 \\
\hline \multicolumn{6}{|l|}{ 3.Number of cysts } \\
\hline 1 & 22 & 73.3 & 20 & 66.7 & \multirow[t]{3}{*}{1.000} \\
\hline 2 & 6 & 20.0 & 8 & 26.7 & \\
\hline$>3$ & 2 & 6.7 & 2 & 6.7 & \\
\hline \multicolumn{6}{|l|}{ 4.Liver lobe } \\
\hline Right & 20 & 66.7 & 14 & 46.7 & \multirow{3}{*}{0.605} \\
\hline Left & 4 & 13.3 & 6 & 20.0 & \\
\hline Both & 6 & 20.0 & 10 & 33.3 & \\
\hline
\end{tabular}




\begin{tabular}{|c|c|c|c|c|c|}
\hline \multirow[t]{2}{*}{ Parameters } & \multicolumn{2}{|c|}{$\begin{array}{l}\text { Laparoscopic } \\
\text { Group }\end{array}$} & \multicolumn{2}{|c|}{ Open Group } & \multirow{2}{*}{$P$ - value } \\
\hline & $n=30$ & $(\%)$ & $\mathrm{n}=\mathbf{3 0}$ & $(\%)$ & \\
\hline \multicolumn{6}{|c|}{ 1. Intraoperative complications } \\
\hline Spillage & 4 & 13.3 & 2 & 13.3 & \\
\hline Bleeding & 0 & 0 & 2 & 13.3 & 1.000 \\
\hline Iatrogenic liver injury & 2 & 6.7 & 0 & 0 & \\
\hline Cystobiliary communication & 0 & 0 & 8 & 13.3 & \\
\hline \multicolumn{6}{|c|}{$\begin{array}{l}\text { 2. Post-operative mobilization } \\
\text { (days) }\end{array}$} \\
\hline 1 & 18 & 60.0 & 0 & 0 & \\
\hline 2 & 12 & 40.0 & 6 & 20.0 & 0.246 \\
\hline 3 & 0 & 0 & 24 & 80.0 & \\
\hline \multicolumn{6}{|l|}{ 3. Drain removal (days) } \\
\hline $1-2$ & 0 & 0 & 0 & 0 & \\
\hline $3-4$ & 30 & 100.00 & 0 & 0 & $0.011 *$ \\
\hline $5-6$ & 0 & 0 & 22 & 73.3 & \\
\hline $7-10$ & 0 & 0 & 8 & 26.67 & \\
\hline \multicolumn{6}{|c|}{ 4. Post-operative complication } \\
\hline biliary leak & 0 & 0 & 8 & 13.3 & 0.042 \\
\hline surgical site infection & 0 & 0 & 10 & 33.3 & \\
\hline \multicolumn{5}{|l|}{ 5. Hospital stay } & \\
\hline $1-3$ & 10 & 33.3 & 0 & 0 & \\
\hline 3-6 & 20 & 66.67 & 0 & 0 & $0.001^{* *}$ \\
\hline $7-10$ & 0 & 0 & 12 & 40.0 & \\
\hline $11-14$ & 0 & 0 & 10 & 33.3 & \\
\hline $15-18$ & 0 & 0 & 8 & 13.3 & \\
\hline
\end{tabular}

\begin{tabular}{|c|c|c|c|}
\hline Baseline Variables & Laparoscopic Group & Open Group & $P$ - value \\
\hline 1. Age (years) & $46.67 \pm 9.76$ & $42.67+14.67$ & 0.387 \\
\hline 2. Number of cysts & $1.33 \pm 0.62$ & $1.40 \pm 0.63$ & 0.772 \\
\hline 3. $\quad$ Size of cysts $(\mathrm{cms})$ & $8.07 \pm 3.10$ & $11.27 \pm 3.17$ & $0.009^{*}$ \\
\hline $\begin{array}{l}\text { 4. Post-operative analgesia } \\
\text { requirement }\end{array}$ & $2.27 \pm 0.46$ & $5.40 \pm 0.83$ & $<0.001^{* *}$ \\
\hline 5. Drain removal day & $3.73+1.28$ & $5.40 \pm 2.92$ & $<0.011^{*}$ \\
\hline $\begin{array}{ll}\text { 6. } & \text { Postoperative hospital } \\
\text { stay }\end{array}$ & $4.47 \pm 1.06$ & $12.00 \pm 3.21$ & $<0.001^{* *}$ \\
\hline
\end{tabular}

\section{* Statistically significant ${ }^{* *}$ highly significant}

\section{DISCUSSION}

There are various treatment modalities for liver hydatid disease including medical management, PAIR (Puncture, Aspiration, Injection, Reaspiration) or combination of both. But surgery was and remains the mainstay for complete healing.(6) Choice is between open conventional surgery and newer laparoscopic surgery. Due to its prolonged learning curve and limited exposure to laparoscopic technique, wide acceptancy is still limited regarding concerns about improper evacuation of cysts, possibility of intra peritoneal dissemination and subsequent high recurrence rate. In fact, the real risk of spillage after laparoscopy is much lower than open surgery. $(9)$ and the short term recurrence rates varies between $0-9 \%$ after laparoscopic and between $0-30 \%$ following open surgery.(10)

Very few series are available which compare the results of open versus laparoscopic surgery, hence our series has been a learning experience towards a comparative analysis. The largest published series of 59 patients by Florin Zaharie et al. (2013).(11) has also confirmed the efficacy of laparoscopy over open surgery in the management of hepatic hydatid disease. The other large series comprise of open surgical management of 391 patients by Heikal Bedioui et al. (2012).(12) and 117 patients by Siddharth S. Rao et al. (2012).(13) A single large laparoscopic series comprising of 66 patients was conducted by Palanivelu C et al. (2006).(14)

In the present study the largest number of patients (70\%) had solitary cysts, mainly located in the right lobe of liver $(56.66 \%)$ with involvement of 2 segments of the liver in $46.66 \%$ cases. Maximum number of cysts were between 6 $12 \mathrm{cms}$ with a mean diameter of $9.9 \mathrm{cms}$. These findings are comparable with the series of Heikal Bedioui, Siddharth S. Rao and Palanivelu $\mathrm{C}$ et al. in respective open and laparoscopic groups. None of the laparoscopic patients of this series had any 
cysts in segments I, II, VII (which are considered blind areas in laparoscopic surgery as they are not easily accessible and visualized).

Intraoperative spillage $(13.3 \%)$ and iatrogenic liver injury $(6.7 \%)$ in group I patients of this series does not compare with the findings of Palanivelu $\mathrm{C}$ et al. (Who has no complications) except cystobiliary communication seen in $13.5 \%$ patients. Intraoperative complications in the open cases in this series are comparable with those of Siddharth S. Rao and Heikal Bedioui et al. We had 8 patients (13.3\%) of post-operative biliary leak in group II (Due to cysto biliary communication), whereas Heikal Bedioui et al. reported $31.9 \%$ of patients with postoperative biliary leak. Postoperative morbidity rate was significantly negligible in laparoscopic group due to lower incidence of complications. (0 versus $13.3 \%, p=0.042$ ) and shorter hospital stay (Average 34 days versus $10-12$ days, $\mathrm{p}=0.001^{*}$ ) with no disease or procedure related mortality in either group. Similar results have been reported by Palanivelu $\mathrm{C}$ et al and Florin Zaharie et al.(14,11)

The encouraging results favouring laparoscopic surgery namely significantly lower postoperative morbidity, shorter hospital stay and rapid healing, should motivate enhanced use of laparoscopy as a prime approach towards liver hydatidosis. The only limitations are thorough preoperative evaluation of relation of cysts with biliary tree and avoiding patients with cyst in laparoscopic inaccessible segments (I, II, VII). Barring these limitations there are no other real contraindications for laparoscopic surgery and following wider exposure to the skills of laparoscopy and the surgeons faster learning curve, this minimally invasive approach will surely be the front runner of surgical management in the near future.

\section{CONCLUSION}

Liver hydatid disease is a complex and dynamic disease confronting both physicians and surgeons worldwide. Due to the various phases of the disease (Growing phase or involution phase of cysts) no "one size fits all" approach can be adopted and efficacious choice of therapy is of utmost importance. Surgery remains the mainstay of management, with the choices of open or laparoscopic surgery. Appropriate patient selection is mandatory before laparoscopic surgery in terms of location of cysts - segments 1 and 7 , size of cysts $>9-10 \mathrm{cms}$ and presence of biliary communications). If these morbidity predictors are judiciously monitored, then laparoscopic surgery provides a safe and efficacious approach to all types of liver hydatid cysts and has well known benefits in terms of early recovery, shorter hospital stay, minimum morbidity and faster return to work. Hence, it is worthy to consider laparoscopy over conventional surgery as a viable alternative for the management of uncomplicated liver hydatid disease.

\section{REFERENCES}

1. Romero-Torres R, Campbell JR. An interpretive review of the surgical treatment of hydatid disease. Surg Gynecol Obstet. 1965 Oct;121(4):851-864.

2. Buttenschoen $\mathrm{K}$, Buttenschoen D. Echinococcus granulosus infection: the challenge of surgical treatment. Langenbecks Arch Surg 2003;388:218-230.

3. King CH. Cestodes (tapeworms). In : Mandell GL, Bennet JE, Dolin R, eds, Principles and practice of Infectious Diseases. $4^{\text {th }}$ edition. New York, NY: Churchill Livingstone; 1995; 2544-2553.

4. Huizinga WKJ, Grant CS, Daar AS. Hydatid disease. In: Morris PJ, Wood WC, eds. Oxford Textbook of Surgery. $2^{\text {nd }}$ edition. New York, NY: Oxford University Press; 2000;3298-3305.

5. Kammear WS, Schantz PM. Echinococcal disease. Infectious dis Clin North Am. 1993;7:605-618.

6. Yagci G, Ustunsoz B, et al. (2005). Results of surgical, laparoscopic and percutaneous treatment for hydatid disease of liver: 10 years' experience with 355 patients. World J Surg 29:1670-1679.

7. Rajeev Sinha, Neeta Sharma. Abdominal Hydatids: A minimally invasive approach. JSLS, 2001 JulSep;5(3):237-240.

8. Hanan R Rihani, et al. Laparoscopic approach to liver hydatid cyst. Is it safe? JRMS 2005 June;12(2):69-71.

9. Manterola C, Fernandez O, Munoz S, Vial M, Losada H, Carrasco R, et al. (2002). Laparoscopic pericystectomy for liver hydatid cysts. Surg Endosc 16:521-524.

10. Seven R, Berber E, Mercan S, et al. (2002). Laparoscopic treatment of hepatic hydatid disease. Surgery 128:36-40.

11. Florin Zaharie, Dana Bartos, et al. (2013). Open or Laparoscopic treatment for hydatid disease of the liver. A 10-year single institution experience. Surg Endosc 27:2110-2116.

12. Heikal Bedioui, et al. Predictive factors of morbidity after surgical treatment of hepatic hydatid cyst. The Pan African Medical Journal. 2012;13:29.

13. Siddharth $\mathrm{S}$ Rao, et al. The spectrum of hydatid disease in rural Central India: An 11-year experience. 2012;5(3):225-230.

14. Palanivelu $\mathrm{C}$, et al. Laparoscopic management of hepatic hydatid disease. JSLS 2006;10:56-62. 